\title{
NSAABJ
}

\section{Study Eksperimen: Pengaruh Gaya Kepemimpinan Terhadap Psychological Safety}

\author{
Siti Rodiah, Agustiawan \\ Fakultas Ekonomi dan Bisnis, Universitas Muhammadiyah Riau, Pekanbaru, Indonesia \\ Email: sitirodiah@umri.ac.id
}

\section{A R T I C L E I N F O}

\author{
Article History: \\ Received: 18 October 2019 \\ Accepted: 31 October 2019 \\ 2019 \\ Keywords: \\ Leasership Style \\ Psychological Safety \\ Experiment Design
}

Available online: 20 November

\begin{abstract}
A B S T R A C T
This study aims to compare the two leadership styles, namely transformational (intellectual stimulation and inspirational motivation) and transactional (contingency reward and $M B E$ Active) in influencing psychological safety by using a $2 \times 2$ experimental design beetwen subject. The sample in this study were accounting students of the University of Muhammadiyah Riau force 2016 who took courses in management accounting and management control systems. Based on the results of hypothesis testing conducted using an independent sample t-test, it was found that managers who have superiors who have intellectual stimulation and contingency reward will be free to express their problems to superiors (psychological safety) compared to managers who have superiors with an inspirational motivation and MBE Active style. The results of this study are expected to improve the psychological safety of managers and all staff employees in a company to express their problems without fear and anxiety so that the company's goals can be achieved.
\end{abstract}

\section{Pendahuluan}

Dunia bisnis saat ini dihadapkan dengan berbagai tantangan diantaranya adalah tantangan neo klasik dan klasikal. Tantangan klasikal berasal dari kekurangan tenaga kerja, permintaan tidak pasti, pengetahuan yang tidak memadai, sedangkan yang termasuk ke dalam tantangan neo-klasik adalah perubahan adopsi, retensi pelanggan dan ketahanan dalam rantai pasokan (Antony \& Gupta, 2019). Lebih lanjut, Antony dan Gupta (2019) menyatakan bahwa dalam menghadapi tantangan tersebut, banyak perusahaan besar telah mengupayakan peningkatan proses bisnis inisiatif. Namun, upaya-upaya tersebut mengalami kegagalan dan kegagalan-kegagalan yang terjadi diakibatkan oleh kurangnya komitmen dan dukungan dari atasan, komunikasi yang lemah, tim yang tidak kompeten, pelatihan dan pembelajaran yang tidak memadai, pemilihan metode dan alat yang salah, sistem / budaya penghargaan dan pengakuan yang tidak pantas, dan pemantauan dan kontrol yang tidak konsisten (kurangnya pengawasan ahli). Ketika perusahaan gagal menghadapi tantangan yang ada maka perusahaan tersebut berpotensi akan mengalami kegagalan dalam persaingan dunia bisnis saat ini.

Penelitian ini akan berfokus pada tantangan dari perubahan adopsi dan pengetahuan yang belum memadai. Perubahan adopsi dan pengetahuan yang belum memadai dapat menimbulkan masalah dalam perusahaan ketika terdapat individu atau karyawan yang 
gagal dalam mengadopsi perubahan dan ilmu yang dimilikinya tidak dapat memecahkan permasalahan tersebut. Oleh sebab itu, solusi yang dapat diberikan adalah dengan memberitahukan permasalahannya kepada atasan atau rekan yang memiliki pengetahuan terkait. Dearman dan Shield (2005) dan Dilla dan Steinbart (2005) mengungkapkan bahwa individu yang memiliki pengetahuan relevan dengan masalah atau tugas tertentu dapat mengurangi bias dan menghasilkan keputusan lebih tepat karena ketersediaan informasi yang membantu pengambilan keputusaan. Namun, tidak semua individu yang menghadapi masalah mau untuk menceritakan permasalahannya kepada orang lain. Hal ini disebabkan oleh perasaan tidak nyaman dari diri individu karena mereka beranggapan pihak lain tersebut akan menyudutkannya atau bahkan dapat merusak image dari individu tersebut.

Kahn (1990) dalam penelitiannya menemukan bahwa yang dapat memengaruhi kesediaan individu untuk mempekerjakan atau mengekspresikan dirinya secara fisik, kognitif, dan emosional selama bekerja adalah psychological safety. Psychological safety mengacu kepada keyakinan yang dimiliki individu bahwa dirinya mampu menunjukkan dan melibatkan dirinya dalam pekerjaan tanpa takut konsekuensi negatif yang akan menimpa citra diri, status maupun karirnya (Kahn, 1990). Selain itu, psychological safety juga mendorong iklim yang ditandai dengan kepercayaan interpersonal dan saling menghormati antar anggota tim (Edmondson, 1999) serta membantu mengatasi pembelaan diri atau kecemasan belajar individu yang terjadi ketika data yang disajikan kepada mereka bertentangan dengan harapan (Schein, 1993).

Oleh sebab, psychological safety harus ditingkatkan dalam perusahaan. Ortega et al. (2014) menyatakan bahwa psychological safety dalam sebuah perusahaan dapat ditingkatkan dengan bantuan dan arahan dari atasan dimana dia bekerja. Penelitian terkait psychological safety telah banyak diteliti antara lain Edmondson dan Roloff (2009) dalam penelitiannya menemukan gaya kepemimpinan dapat mendorong psychological safety dengan memberikan masukan dan umpan balik ketika bawahan telah terbuka mengakui kesalahan sendiri. Detert dan Burris (2007) menemukan bahwa pemimpin dengan gaya transformasional lebih mungkin untuk menumbuhkan psychological safety karyawan dan Peng dkk. (2016) menemukan bahwa pemimpin yang memiliki gaya kepemimpinan stimulasi intelektual lebih baik dalam mengarahkan motivasi karyawan dibandingkan dengan kepemimpinan yang memiliki gaya kepemimpinan motivasi inspirasi, perhatian individu, dan pengaruh individual). Selain gaya kepemimpinan transformasional, ditemukan juga gaya kepemimpinan transaksional yang dapat memengaruhi psychological safety. Podsakoff (2010) menemukan bahwa gaya kepemimpinan transaksional imbalan kontigen lebih baik dalam mempengaruhi perilaku karyawan dibandingkan dengan gaya kepemimpinan transaksional MBE aktif.

Berdasarkan hasil penelitian di atas, penelitian ini ingin membandingkan gaya kepemimpinan transformasional-stimulasi intelektual bila digabungkan dengan gaya kepemimpinan transaksional-contingency reward apakah lebih mempengaruhi psychological safety karyawan daripada kepemimpinan transformasional-motivasi inspirasional bila digabungkan dengan gaya kepemimpinan transaksional-MBE Aktif. Penelitian ini merupakan pengembangan dari penelitian Rodiah dan Nahartyo (2018) yaitu dengan menggunakan $2 \times 2$ between-subject factorial experiment design untuk membandingkan psychological safety dengan kombinasi intellectual stimulation + contingent reward versus inspirational motivation + MBE Aktif. Hasi penelitian ini diharapkan dapat membantu perusahaan dalam meningkatkan psychological safety sehingga segala permasalahan dapat diatasi dan dapat menghadapi persaingan bisnis yang kompetitif. Artikel ini dilanjutkan sebagai berikut. Pada bagian selanjutnya akan disajikan tinjauan pustaka dan pengembangan hipotesis yang akan menjelaskan hubungan antar variabel dalam penelitian ini. Pada bagian ketiga, penelitian ini menyediakan desain eksperimen yang akan digunakan untuk menjawab hipotesis yang disediakan di bagian sebelumnya. Hasil akan disampaikan pada 
bagian ke empat dan akan dijelaskan dan dikaitkan dengan penelitian selanjutnya dan kemajuan bisnis di masa depan.

\section{Tinjauan Pustaka dan Pengembangan Hipotesis}

\subsection{Goal Path Theory}

Goal path theory yang dikemukakan oleh House (1971) menjelaskan bahwa seorang pemimpin harus memiliki kemampuan yang baik agar dapat dipergunakan untuk melengkapi dan mengimbangi kekurangan bawahannya. Selain itu, teori ini juga menyediakan cara bagi para pemimpin untuk mendorong dan mendukung karyawan mereka dalam mencapai tujuan mereka, salah satunya adalah dengan memberikan reward.

House dan Mitcheli (1975) menjelaskan bahwa motivasi sangat penting dalam menerapkan path goal theory karena dengan adanya motivasi, pemimpin dapat mengarahkan bawahannya dalam mencapai tujuan mereka. Motivasi dapat dilakukan dengan adanya pemberian penghargaan dan pengarahan kepada bawahan mengenai jalur mana yang dipilih untuk bekerja sehingga tujuan dan fokus mereka tidak terganggu. Selanjutnya, menurut path goal theory, seorang pemimpin harus fokus pada jenis perilaku kepemiminan mana yang harus dipilihnya karena ini semua bergantung pada situasi dan bawahan mereka. Hal ini memungkinkan para pemimpin untuk bekerja pada tujuan departemen, tetapi juga menyatukan ini dengan tujuan organisasi.

\subsection{Psychological Safety}

Psychological safety didefinisikan sebagai kemampuan seseorang untuk bersosialisasi dengan orang lain tanpa takut dengan konsekuensi negatif atas citra diri, status dan karirnya (Kahn, 1990). Lebih lanjut, Kahn (1990) menyatakan bahwa dalam lingkungan pekerjaan, psychological safety merujuk kepada kenyamanan individu untuk terlibat dalam sebuah pekerjaan dan apabila pekerjaannya mengalami kegagalan, indvidu tersebut tidak akan takut untuk mengakuinya karena dia mengharapkan adanya bantuan dari pihak lain.

\subsection{Gaya Kepemimpinan}

Yukl (2010) mendefinisikan kepemimpinan sebagai suatu proses dalam memengaruhi orang lain agar memahami dan melaksanakan prosedur yang diberikan serta memfasilitasi individu dan kelompok untuk mencapai tujuan bersama. Pemimpin dalam memengaruhi bawahannya memiliki gaya yang berbedabeda. Bass (1985) membagi gaya kepemimpinan menjadi dua yaitu gaya kepemimpinan transformasional dan transaksional. Transformasional mencakup dua hal yaitu intellectual stimulation dan inspirational motivation. Intellectual stimulation ditandai dengan sikap seorang atasan yang meminta bawahannya untuk memberikan pandangan terkait permasalahan dan pertimbangan mereka dalam pengambilan keputusan. Inspirational motivation ditunjukkan oleh atasan yang menginspirasi dan memotivasi karyawannya untuk bertindak melalui penjabaran visi dan misi yang ingin dituju (Bass, 1985). Sedangkan transaksional dalam penelitian ini menggunakan dua indikator yaitu contingency reward dan MBE aktif. Contingency reward didefinisikan sebagai bonus atau insentif yang diberikan oleh atasan kepada bawahan sedangkan MBE aktif adalah hukuman yang diberikan atasan kepada bawahannya untuk mengantisipasi kesalahan yang dilakukan oleh bawahan (Breevaart et al., 2014).

\subsection{Pengembangan Hipotesis}

Bass dan Avolio (1990) menyatakan bahwa kepemimpinan transaksional dapat digunakan secara efektif apabila organisasi dalam keadaan stabil, sedangkan kepemimpinan transformasional sangat penting bagi organisasi ketika menghadapi perubahan yang cepat dan tidak stabil. Ketika organisasi menghadapi dua kondisi tersebut, Bass dan Avolio (1993) menyarankan agar organisasi tetap mempergunakan basis kepemimpinan transaksional yang efektif tetapi tetap memanfaatkan kepemimpinan transformasional untuk menghasilkan perubahan dalam budaya organisasi. Lebih lanjut, Howell dan Avolio (1993) menyatakan bahwa kepemimpinan transformasional melengkapi kepemimpinan transaksional dan pemimpin yang efektif sering melengkapi kepemimpinan 
transaksional dengan kepemimpinan transformasional. Oleh sebab itu, di dalam memengaruhi bawahannya, antara kepemimpinan transformasional dan transasksional dapat dipergunakan secara bersama-sama sesuai dengan situasi dan kondisi yang dihadapi oleh bawahannya. Hal ini sesuai dengan path goal theory yang menjelaskan bahwa seorang pemimpin harus fokus pada jenis perilaku kepemimpinan mana yang harus dipilihnya karena ini semua bergantung pada situasi dan bawahan mereka (House \& Mitchell, 1975).

Ketika bawahan sedang mengalami kesulitan dalam pekerjaanya, atasan harus membantu bawahannya dalam menemukan jalan keluar serta memberikannya motivasi berupa imbalan kepada bawahan agar tujuannya dapat tercapai. Puni, Mohammed dan Assamoah (2018) dalam penelitiannya mengemukakan bahwa para karyawan di Ghanaian banks dapat meningkatkan job satisfaction mereka melalui pemimpin yang dapat menstimulasi bawahannya untuk berfikir dan mengatasi permasalahan mereka secara kreatif. Selain itu, pemimpin juga harus memiliki skema imbalan kontingen untuk mengenali orang-orang yang mampu mencapai tujuan dan target yang ditetapkan. Hasil ini sejalan dengan penelitian Judge dan Picollo (2004) yang menemukan bahwa contingent reward memiliki hubungan yang kuat dengan transformasional dalam memengaruhi bawahannya.

Jika dikaitkan dengan psychological safety, kepemimpinan intellectual stimulation dan contingent reward memiliki perannya dalam meningkatkan keberanian bawahan untuk menceritakan permasalahan yang dihadapinya. Scholl (1999) berpendapat bahwa kepemimpinan stimulasi intelekual akan membantu bawahan yang sedang tertimpa kesulitan dengan memberikan beberapa alternative yang dapat dipilih oleh bawahan dan Zhou et al. (2012) menemukan bahwa rendahnya intellectual stimulation seorang pemimpin dapat memengaruhi kegiatan promosi menjadi kurang semangat dan membuat tim mengalami frustasi.

Berdasarkan teori dan hasil penelitian di atas, maka hipotesis dari penelitian ini adalah:
$\mathbf{H}_{1}$ : Individu yang dihadapkan pada atasan intellectual stimulation dan contingent reward akan memiliki keamanan psikologis lebih tinggi dibandingkan dengan individu yang dihadapkan pada atasan inspirational motivation dan MBE Aktif.

\section{Metode Penelitian}

\subsection{Desain Eksperimen}

Penelitian ini menggunakan $2 \times 2$ betweensubjects design untuk memanipulasi kondisi psychological safety partisipan dengan didorong oleh gaya kepemimpinan transformasional (intellectual stimulation, inspirational motivation) dan gaya kepemimpinan transaksional (contingent reward, MBE Aktif). Psychological safety dalam penelitian ini didefinisikan sebagai keyakinan yang dimiliki oleh individu untuk berbicara dalam kelompok tanpa adanya rasa malu, penolakan dari orang lain atau sampai mengurangi citra diri dan status (Kahn, 1990). Indikator ukuran psychological safety merujuk pada penelitian Siemsens et al. yaitu saya dapat memberi tahu rekan kerja dengan aman tentang kesalahan yang saya buat, saya merasa nyaman memberi tahu rekan kerja saya tentang kesalahan yang saya buat, aman untuk mengakui kesalahan yang saya buat pada rekan kerja saya (Siemsen, Roth, Balasubramanian, \& Anand, 2009). Item pernyatan diukur menggunakan skala likert 5 poin (sangat tidak setuju hingga sangat setuju).

Tabel 1. Disain eksperimen

\begin{tabular}{llcc}
\hline & & \multicolumn{2}{c}{ Transaksional } \\
\cline { 3 - 4 } & & $\begin{array}{c}\text { Contingent } \\
\text { reward }\end{array}$ & MBE Aktif \\
\hline $\begin{array}{l}\text { Transfor- } \\
\text { mational }\end{array}$ & $\begin{array}{l}\text { Intellectual } \\
\text { stimulation }\end{array}$ & $\mathrm{A}$ & $\mathrm{B}$ \\
\cline { 2 - 4 } & $\begin{array}{l}\text { Inspirational } \\
\text { motivation }\end{array}$ & $\mathrm{C}$ & $\mathrm{D}$ \\
\hline
\end{tabular}

\subsection{Partisipan}

Partisipan eksperimen dalam penelitian ini sebanyak 100 orang mahasiswa angkatan 2016 program studi Akuntansi Universitas Muhammadiyah Riau dengan kriteria telah mendapatkan mata kuliah akuntansi manajemen dan sistem pengendalian manajemen serta mahasiswa yang sedang bekerja dengan latar belakang pekerjaan yang berbeda. Alasan pemilihan mahasiswa sebagai 
sampel penelitian ini mahasiswa dapat menjadi pengganti atau proksi praktisioner dalam ekperimen pembuatan keputusan (Liyanarichi, 2007).

Sedangkan untuk pilot test dilakukan kepada 30 mahasiswa Akuntansi (S1) Fakultas Ekonomi dan Bisnis Universitas Muhammadiyah Riau yang tidak termasuk dalam sampel penelitian. Pilot test dilakukan dengan tujuan untuk mengetahui apakah kasus yang diberikan dapat dipahami atau tidak oleh partisipan. Evaluasi hasil pilot test dapat berbentuk perbaikan agar persepsi dan bahasa yang digunakan dipahami lebih mudah oleh partisipan.

Setelah eksperimen dilakukan, ditemukan 9 kuesioner yang tidak lulus manipulasi cek dan harus dikeluarkan dari analisis data dan kuesioner yang lulus berjumlah 91 kuesioner. Partisipan yang lulus manipulasi cek terdiri dari 26 pria dan 65 wanita dengan rata-rata usia 22 tahun dan lama bekerja 3 tahun.

\subsection{Prosedur dan Skenario Eksperimen}

Eksperimen ini dilaksanakan kepada mahasiswa secara sukarela tanpa ada paksaan apapun. Eksperimenter meminta izin kepada dosen dan mahasiswa yang sedang melaksanakan perkuliahan di dalam kelas. Setelah mendapatkan izin, eksperimenter memperkenalkan diri dan menjelaskan terlebih dahulu tata cara dalam pengisian kuesioner. Pelaksanaan eksperimen berlangsung selama 30 menit.

Kuesioner terdiri dari 3 lembar yaitu lembar pertama kasus atau skenario yang menceritakan tentang karyawan yang memiliki atasan dengan gaya kepemimpinan berbedabeda. Karyawan tersebut diberikan tugas oleh atasannya, namun di tengah pengerjaan tersebut, karyawan memiliki beberapa kendala. Berdasarkan gaya kepemimpinan yang dimiliki oleh atasannya, penelitian ini ingin melihat apakah karyawan tersebut akan menceritakan permalahannya atau tidak. Kemudian, di lembar kedua berisi manipulasi cek untuk menguji tingkat pemahaman partisipan atas kasus yang diberikan. Lembar ketiga berisi data demografi responden dan ucapan terimakasih sebagai pertanda berakhirnya eksperimen tersebut.

\subsection{Uji Hipotesis}

Uji hipotesis dalam penelitian ini menggunakan independent sample t-test yang digunakan untuk menguji hipotesis 1 dengan membandingkan nilai total mean sel A \& B dengan nilai total mean sel C \& D. Hipotesis 1 didukung apabila nilai total mean sel A \& B lebih besar daripada nilai total mean sel C \& D. Sebelum melakukan uji hipotesis dengan menggunakan independent sample t-test, data harus berdistribusi normal dan lulus uji homogenitas. Uji normalitas data menggunakan saphiro wilk dan homogenitas menggunakan levene test yang diolah dengan bantuan software SPSS 22.

\section{Hasil Penelitian dan Pembahasan}

\subsection{Hasil Uji Normalitas Data}

Berdasarkan hasil uji normalitas data di atas, ditunjukkan bahwa permasing-masing sel memiliki nilai signifikansi di atas 0,05 sehingga dapat disimpulkan bahwa data tersebut berdistribusi normal dan dapat digunakan untuk uji selanjutnya yaitu uji hipotesis dengan independent sample t-test.

Tabel 2. Hasil Uji Normalitas

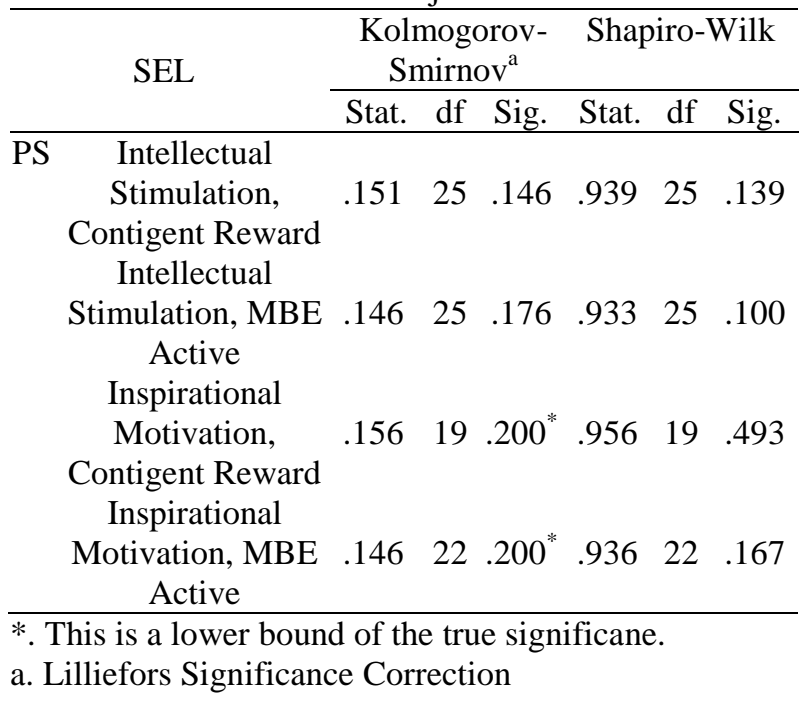

\subsection{Hasil Uji Hipotesis}

Hipotesis 1 yang diajukan dalam penelitian ini adalah manager yang dihadapkan pada atasan yang menstimulasi karyawannya dan memberikan reward akan mempunyai psychological safety yang lebih tinggi dibandingkan dengan manager yang dihadapkan pada atasan yang menstimuli karyawannya dan memberikan hukuman. Pengujian H1 untuk menguji apakah ada perbedaan terkait kondisi psychological safety 
manager unit bisnis antara kepemimpinan transformasional stimulasi intelektual dengan kepemimpinan transformasional motivasi inspirasi. Pengujian hipotesis ini menggunakan Independent Sample T-Test, yaitu dengan membandingkan nilai total mean sel A \& B dengan nilai total mean sel C \& D. H1 didukung apabila nilai total mean sel A \& B lebih besar daripada nilai total mean sel C \&D.

Tabel 3. Hasil Uji Hipotesis Menggunakan Independent Samples Test

\begin{tabular}{|c|c|c|c|c|c|c|c|c|c|c|}
\hline & & $\begin{array}{r}\text { Leven } \\
\mathrm{Eq} \\
\mathrm{V}\end{array}$ & $\begin{array}{l}\text { Test for } \\
y \text { of } \\
\text { ces }\end{array}$ & & & & t-test fo & $\begin{array}{l}\text { Equality of } \\
\text { eans }\end{array}$ & $\begin{array}{r}95 \% \mathrm{C} \\
\text { Inter } \\
\text { Dif }\end{array}$ & $\begin{array}{l}\text { nfidence } \\
\text { l of the } \\
\text { rence }\end{array}$ \\
\hline & & $\mathrm{F}$ & Sig. & $\mathrm{t}$ & Df & $\begin{array}{c}\text { Sig. } \\
\text { (2-tailed) }\end{array}$ & $\begin{array}{c}\text { Mean } \\
\text { Difference }\end{array}$ & $\begin{array}{l}\text { Std. Error } \\
\text { Difference }\end{array}$ & Lower & Upper \\
\hline PS & $\begin{array}{l}\text { Equal variances } \\
\text { assumed }\end{array}$ & .312 & .579 & 1.997 & 48 & .052 & 1.000 & .501 & -.007 & 2.007 \\
\hline & $\begin{array}{l}\text { Equal variances } \\
\text { not assumed }\end{array}$ & & & 1.997 & 47.323 & .052 & 1.000 & .501 & -.007 & 2.007 \\
\hline
\end{tabular}

Berdasarkan hasil uji Independent Sample ttest di atas menunjukkan bahwa nilai total mean sel A \& B sebesar 48 dan nilai total mean sel C \& D sebesar 47,323. Dari hasil tersebut, dapat ditarik kesimpulan sementara bahwa terdapat perbedaan kondisi psychological safety manager unit bisnis antara kepemimpinan transformasional stimulasi intelektual + contingency reward dengan kepemimpinan transformasional stimulasi intelektual + MBE Aktif (48>47,323). Selanjutnya, hasil F hitung levene t-test sebesar 0.312 dengan signifikansi pada 0,579 . Mengingat signifikansi di atas 0,05 (0.329>0,05), maka dapat disimpulkan bahwa kedua kelompok memiliki varians yang sama (homogen). Nilai t pada equal variances assumed adalah 1,997 dengan signifikansi 0,052. Jadi, dapat disimpulkan kembali bahwa terdapat perbedaan kondisi psychological safety manager unit bisnis antara kepemimpinan transformasional stimulasi intelektual + contingency reward dengan kepemimpinan transformasional stimulasi intelektual + MBE Aktif. Sehingga, manajer yang dihadapkan pada atasan yang menstimulasi karyawannya akan memiliki psychological safety lebih tinggi. Berdasarkan hasil evaluasi di atas, dapat dinyatakan bahwa hipotesis (H1) yang diajukan dalam penelitian ini didukung.

\subsection{Pembahasan}

Berdasarkan hasil uji-t independen, hipotesis 1 dinyatakan bahwa hipotesis diterima. Hasil hipotesis 1 konsisten dengan Puni, Mohammed dan Assamoah (2018) yang menemukan bahwa pemimpin yang dapat menstimulasi karyawannya dan memberikan imbalan yang sesuai dengan kinerjanya akan lebih leluasa untuk menceritakan semua permasalahan yang dihadapinya sehingga pekerjaan yang dikerjakannya akan dapat terselesaikan dengan baik dan tentunya tujuan perusahaan dapat tercapai. Hal ini juga sesuai dengan path goal theory yang menyatakan bahwa gaya kepemimpinan harus dapat disesuaikan dengan kondisi dan situasi bawahannya (House \& Mitchell, 1975).

\section{Kesimpulan}

Penelitian ini membandingkan dua kondisi bawahan yang dihadapkan oleh atasan yang memilki gaya kepemimpinan intellectual stimulation dan kepemimpinan contingent reward terhadap psychological safety dengan inspirational motivation dan MBE Aktif. Berdasarkan hasil penelitian tersebut ditemukan bahwa atasan yang menstimulasi bawahannya dan memberikan imbalan atas jerih payahnya akan lebih memiliki psychological safety yang tinggi dibandingkan dengan inspirational motivation dan $\mathrm{MBE}$ Aktif. Hasil penelitian ini diharapkan dapat membantu atasan dalam meningkatkan psychological safety bawahannya agar semua cita-cita perusahaan dapat tercapai.

Penelitian ini memiliki keterbatasan yaitu pengetahuan responden terkait balanced scorecard belumlah cukup dalam dikarenakan ilmu terkait balanced scorecard tersebut hanya dijelaskan singkat di mata kuliah akuntansi managemen dan system pengendalian manajemen, sehingga penelitian selanjutnya 
dapat memberikan sedikit rincian terkait balanced scorecard dan bagaimana pengimplementasiannya saat ini. Selanjutnya, penelitian ini hanya berfokus pada kepemimpinan intellectual stimulation, inspirational motivation, contingent reward dan MBE aktif dalam memengaruhi psychological safety bawahannya, untuk penelitian berikutnya dapat menggunakan indikator kepemimpinan transformasional dan transaksional lainnya yaitu perhatian individu, dan pengaruh individual serta MBE pasif dalam memengaruhi psychological safety.

\section{Ucapan Terima Kasih}

Penelitian ini dibiayai Kementerian Riset, Teknologi dan Pendidikan Tinggi Republik Indonesia (Ristekdikti) melalui skema hibah Penelitian Dosen Pemula (PDP) tahun 2019.

\section{Daftar Pustaka}

Antony, J., \& Gupta, S. (2019). Top ten reasons for process improvement project failures. International Journal of Lean Six Sigma, 10(1), 367-374. https://doi.org/10.1108/IJLSS-11-20170130

Bass, B.M. (1985). Leadership and performance beyond expectations. New York: Free Press.

Bass, B.M. and Avolio, B.J. (1990), Transformational Leadership Development: Manual for the Multifactor Leadership Questionnaire, Consulting Psychologists Press, Palo Alto, CA.

Bass, B.M. and Avolio, B.J. (1993), "Transformational leadership and organizational culture", Public Administration Quarterly, Vol. 17 No. 1, pp. 112-121.

Breevaart, K., Bakker, A., Hetland, J., Demerouti, E., Olsen, O. K., \& Espevik, R. (2014). Daily transactional and transformational leadership and daily employee engagement. Journal of Occupational and Organizational Psychology, 87(1), 138-157. https://doi.org/10.1111/joop.12041

Dearman, D. \& M. Shields. (2005). Avoiding accounting fixation: determinants of of cognitive adaptation to differences in accounting method. Contemporary
Accounting Research 22:351-384.

Detert, J. R. \& Burris E. R. (2007). leadership behavior and employee voice: is the door really open?. Academy of Management Journal. Vol. 50, No. 4, 869-884.

Dilla, W. N., \& Steinbart, P. J. (2005). Relative weighting of common and unique Balanced Scorecard measures by knowledgeable decision makers. Behavioral Research in Accounting 17: 4353.

Edmondson, A. (1999). Psychological safety and learning behavior in work teams. Administrative Science Quarterly, 44(2), 350-383. https://doi.org/10.2307/2666999

Edmondson, A. C., \& Roloff, K. S. (2009). Overcoming barriers to collaboration: Psychological safety and learning in diverse teams. In E. Salas, G. F. Goodwin, \& C. S. Burke Eds., Team effectiveness in complex organizations: Cross-disciplinary perspectives and approaches 34: 183-208. New York: Routledge/Taylor \& Francis Group.

House, R. J. (1971). A Path Goal Theory of Leader Effectiveness. Administrative Science Quarterly, Vol. 16, No. 3 , pp. 321339Published

House, R. J., \& Mitchell, T. R. (1975). PathGoal Theory of Leadership. Washington Univ Seattle Dept of Psychology., (April), 75-67. Retrieved from https://apps.dtic.mil/dtic/tr/fulltext/u2/a009 513.pdf

Howell, J. M. \& Avolio, B. J. (1993). Transformational Leadership, Transactional Leadership, Locus of Control, and Support for Innovation: Key Predictors of Consolidated-Business Unit Performance. Journal of Applied Psychology, 78, 891.

Judge, T. A. \& Piccolo, R. F. (2004). Transformational and transactional leadership: a meta-analytic test of their relative validity, Journal of Applied Psychology, Vol. 89 No. 5, pp. 755-768.

Kahn, W. A. (1990). Psychological conditions of personal engagement and disengamenet at work. Academy of Management Journal, 30(4), 692-724. https://doi.org/10.1103/PhysRevB.36.2607

Liyanarachchi, G. A. (2007). Feasibility of using student subjects in accounting 
experiments: a review, Pacific Account. Rev., vol. 19, no. 1, pp. 47-67, 2007.

Ortega, A1'da. Van den Bossche, Piet. Sa'nchez-Manzanares, Miriam. Rico, Ramo'n. Gilv, Francisco. (2014). The Influence of Change-Oriented Leadership and Psychological Safety on Team Learning in Healthcare Teams. $J$ Bus Psychol 29: 311-321.

Peng, A. C., Hsing-Er, Lin. J.Schaubroeck., E. F. McDonough III., B, Hu., A. Zhang. (2016). CEO Intellectual Stimulation and Employee Work Meaningfulness: The Moderating Role of Organizational Context. Group \& Organization Management 41(2): 203-231.

Podsakoff, Nathan P., P. M. Podsakoff., V. V. Kuskova. (2010). Dispelling misconceptions and providing guidelines for leader reward and punishment behavior. Business Horizons 53: 291-303.

Puni, Albert, Mohammed, Ibrahim, Asamoah, Emmanuel. (2018). Transformational leadership and job satisfaction: the moderating effect of contingent reward, Leadership \& Organization Development Journal.
Rodiah, S., \& Nahartyo, E. (2019). Knowledge Sharing Behaviour: the Effect of Psychological Safety on Balance Scorecard (BSC) Implementation. Journal of Accounting and Investment, 20(1), 23-40.

Schein, E. H. (1993). How can organizations learn faster? The challenge of entering the green room. Sloan Management Review, 34, : 85-92.

Scholl, W. (1999). Restrictive control and information pathologies in organizations. Journal of Social 55(1): 101-118.

Siemsen, E., Roth, A. V., Balasubramanian, S., \& Anand, G. (2009). The influence of psychological safety and confidence in knowledge on employee knowledge sharing. Manufacturing and Service Operations Management, 11(3), 429-447. https://doi.org/10.1287/msom.1080.0233

Yukl, A. Gary. (2010). Leadership on Organizations. Seventh Edition, New Yersey, Prentice Hall.

Zhou, Q., Hirst, G. \& Shipton, H. (2012). Context matters: Combined influence of participation and intellectual stimulation on the promotion focus-employee creativity relationship. Journal of Organizational Behavior 33: 894-909. 